Article

\title{
Beyond Control: Policy Incoherence of the EU Emissions Trading System
}

\author{
Maximilian Willner ${ }^{1, *}$ and Grischa Perino ${ }^{1,2}$ \\ ${ }^{1}$ Department of Socioeconomics, University of Hamburg, Germany \\ ${ }^{2}$ Center for Earth System Research and Sustainability (CEN), University of Hamburg, Germany \\ * Corresponding author (maximilian.willner@uni-hamburg.de)
}

Submitted: 6 August 2021 | Accepted: 28 September 2021 | Published: 17 March 2022

\begin{abstract}
In this article, we explain why the current climate policy mix of the European Union (EU), consisting of the EU Emissions Trading System (ETS) and overlapping policies, is incoherent with respect to emission abatement and cost-effectiveness. The concept of policy coherence guides our analysis in identifying the EU ETS' current dynamic supply adjustment mechanism, the Market Stability Reserve (MSR), to be at the heart of the shortcomings of current market design. Incoherence emerges due to the MSR's quantity-based indicator for scarcity. It only works well for current and past demand fluctuations, but not for anticipated changes in demand, e.g., caused by a member state's fossil-fuel phase-out. As a result, instead of fostering synergies as intended, the MSR undermines coherence by creating backfiring interactions and making precise predictions of overlapping policies' impacts close to impossible. Considering the European Commission's reform proposal of July 2021, we argue that a change in the MSR's parametrisation leaves the fundamental cause of incoherence unaddressed. Based on recent findings in the economics literature, we propose introducing a price-based indicator for scarcity as a solution to substantially reduce the current incoherence of the policy mix.
\end{abstract}

\section{Keywords}

climate policy; emission trading; EU ETS; market stability reserve; overlapping policies; policy analysis; policy coherence

\section{Issue}

This article is part of the issue “Carbon Pricing Under Pressure: Withering Markets?" edited by Jørgen Wettestad (Fridtjof Nansen Institute) and Lars H. Gulbrandsen (Fridtjof Nansen Institute).

(C) 2022 by the author(s); licensee Cogitatio (Lisbon, Portugal). This article is licensed under a Creative Commons Attribution 4.0 International License (CC BY).

\section{Introduction}

Following the United Nations Conference on Environment and Development in Rio de Janeiro in 1992 and the Kyoto Protocol of 1997, the need arose for the European Union (EU) to create a policy infrastructure to achieve its greenhouse gas (GHG) abatement targets. A Union-wide carbon tax was politically infeasible due to the unanimity requirement of fiscal measures. Instead, the EU went for the quantity-based approach of a cap-and-trade scheme that only required a qualified majority (Ellerman \& Buchner, 2007). As of 2021, the European Union Emissions Trading System (EU ETS) regulates roughly 11,000 installations in the energy and heavy industry sectors as well as 600 airlines (European Union, 2003, 2015). Its market mechanism sets a price for GHG emissions in 30 countries and Northern Ireland, covering about $36 \%$ of the EU's $\mathrm{CO}_{2}$-equivalent emissions (European Commission, 2021d). Until recently, it was the world's largest carbon market in terms of regulated emissions (1.38 billion tons in 2020), now being surpassed only by the newly launched Chinese ETS (European Environment Agency, 2021; International Carbon Action Partnership, 2021). Despite several obstacles, the system's cap and thus regulated emissions have decreased by roughly $43 \%$ since 2005, substantially contributing to the EU's climate track record (Bayer \& Aklin, 2020; European Environment Agency, 2020, 2021).

The EU ETS is not a standalone instrument; it interacts with other instruments, which lead to a direct or indirect change in emissions. The overlap in scope constitutes a policy mix mirroring the EU's multi-level 
governance structure. Member states (MS) have interfered with the carbon market by implementing domestic carbon price floors or unilaterally cancelling allowances. Both MS and the EU have passed policies that directly target market participants, e.g., by phasing out coal or setting performance standards. Moreover, overlapping policies target the product markets of industries subject to the EU ETS. Examples are renewable support schemes, energy efficiency standards, and labels for appliances. In short, intended and unintended interactions with other climate and energy policies impacting the system's market outcome are the rule as they affect the demand (and in case of cancellations, the supply) for emission allowances.

We are interested in the coherence of the resulting policy mix, i.e., whether the individual instruments align and work in the same direction, not hampering or even improving performance with regard to the total amount of emissions abated and cost-effectiveness of achieving preset abatement targets. Several previous analyses have focused on which policies overlapping with a fixed-cap ETS lead to a coherent policy mix and how they should be designed (see del Río et al., 2013; van den Bergh et al., 2021). We add to this by focusing on the EU ETS, which no longer features a fixed cap, and its capability to coordinate overlapping policies to promote policy coherence.

For further elicitation, it is important to note the dual role of the EU ETS: As an instrument for putting a price on carbon and regulating emissions, it is an element of the policy mix in its own right. Yet, it also connects all market participants by the shared cap, which implies that any other climate policy affecting any regulated participant changes the availability of allowances for all others as well. If the overall cap on emissions does not respond to the introduction or adjustment of policies overlapping the EU ETS, they do not affect system-wide emissions but merely relocate them in space and time (Eichner \& Pethig, 2019). The impact of this so-called "waterbed effect" on coherence is ambiguous. By taking the climate externality out of the picture for all other policies, regulators are able to focus on further objectives such as energy security, the under-provision of research and development, escaping technological lock-ins, or addressing information asymmetries. The pre-2019 EU ETS that featured a fixed cap could hence be seen as a breakthrough for climate policy coherence. However, as other policies continued to target emission reductions, the waterbed has been perceived as an obstacle rather than a facilitator of coherence because it prevented said climate policies from reducing total emissions.

Partly to address this perceived downside, the EU ETS has been complemented by a dynamic supply adjustment mechanism, the Market Stability Reserve (MSR). First legislated in 2015, reformed in 2018, and operative since 2019, the MSR is meant to promote investment in lowcarbon technologies, dampen allowance price volatility, and reduce the number of unused allowances that had accumulated in previous years (European Union, 2015; Perino \& Willner, 2016, 2017). Most importantly, for the purpose of this article, it is the explicit aim of the MSR to increase synergies with other climate and energy policies (see preamble of European Union, 2015). The idea is to adapt supply based on the quantity of banked allowances held by market participants, officially called the "Total Number of Allowances in Circulation" (TNAC; see European Commission, 2021c), which is used as the indicator for the scarcity of allowances in the system.

The MSR leads to a "puncture" in the waterbed. The supply now responds to changes in demand for allowances and hence to changes caused by other instruments (Perino, 2018). Total abatement achieved by the climate policy mix can therefore add up to more than the reduction prescribed by the baseline trajectory of the system's cap. An overlapping policy that reduces demand in any given year increases the number of allowances banked by firms at the end of that year and hence triggers additional cancellations by the MSR in future years. However, the recent literature has also shown that the flexibility of the cap can backfire, i.e., result in less overall abatement and thereby put the coherence of the policy mix at even greater risk (Gerlagh et al., 2021; Perino et al., 2020; Rosendahl, 2019).

In the following, we investigate the current design of the EU ETS with the MSR and how the latter impacts the coherence of the EU's climate policy mix within the ETS sectors. Moreover, we consider the proposed changes to the MSR published by the European Commission (EC) in the "Fit for 55 Package" as of July 2021. By focusing on the concept of policy coherence, we offer a new perspective towards the current EU climate policy infrastructure and make the key findings of the past three years of economic research on this matter accessible.

\section{Policy Coherence and Carbon Markets}

The concept of policy coherence, e.g., enshrined in Art. 208 of the Treaty of the Functioning of the European Union (European Union, 2012) originates from the development policy and sustainability debate of the $1980 \mathrm{~s}$ (de Jong \& Vijge, 2021; Verschaeve et al., 2016). While there is no universally agreed definition of policy coherence and the concept undergoes constant change, it is based on the idea that overlapping policies can interact with each other's objectives and performance. The interconnectedness of socio-economic systems calls for an alignment of governance systems and their policies to work in the same direction to minimise the cost of policy goal attainment (Sandström et al., 2020; Sianes, 2013). Since the 1990s, the concept has proliferated from development policy to various other policy domains, especially in the EU, where policy-making emanates on different levels of governance. In particular, a distinction can be made between horizontal policy overlap at the EU level and vertical overlap between policies at the EU and MS level (Sandström et al., 2020; Söderberg, 2016). 
Current EU legislation undergoes codified procedures to analyse and minimise detrimental effects on the performance of the existing policy infrastructure. The Impact Assessment Procedure and monitoring as part of the Better Regulation Agenda of 2015 are meant to avoid conflict among interacting policies and to create synergies where possible (European Commission, 2021e). To this end, the "Better Regulation Toolbox" defines coherence as a common principle (European Commission, 2021f, p. 9) so that the choice of policy instruments should involve consideration of ways "to exploit synergies and to avoid undermining the effectiveness of existing instruments or raising compliance costs" (European Commission, 2021f, p. 120). Moreover, the European Commission established the REFIT-Program to reduce redundancies within the EU's policy infrastructure by rephrasing, discarding, or complementing legislation to align it with the legislative environment and reduce the latter's complexity (European Commission, 2019). This shall increase targeted policies' adaptability to each other and their comprehensibility for regulated entities (del Río \& Cerdá, 2017). From this perspective, incoherence also describes a state of policy (inter)action from different levels of governance where at least one side, but likely multiple legislators and affected entities, cannot or do not fully consider the link between their choices and outcomes within the policy mix. Effects of deliberately designed policies amending a given policy mix are then beyond the control of the respective legislator.

In complex governance systems such as the EU's, the use of multiple instruments for shared objectives is the norm and suggests there is an expectation of possible synergies and complementarities (Nilsson et al., 2012; Sorrell \& Sijm, 2003). It depends on the policy mix's design whether an increase in interactions actually results in more incoherence, leading to a loss of performance towards one or several policy goals, including cost-effectiveness (Kern \& Howlett, 2009).

Interactions of policies within a policy mix can be neutral, synergetic, conflicting, or they can even backfire (see Table 1). The latter describes the situation where the policy mix performs worse than one containing only a proper subset of the instruments of the original (van den Bergh et al., 2021).
A close look at interactions is of particular relevance for a climate policy mix featuring an ETS (Coscieme et al., 2021; Fais et al., 2015; Fankhauser et al., 2010). The larger the sectoral scope of an ETS and the more fragmented legislation, implementation, and administration of the climate policy domain, the higher the amount and interdependency of potential interactions between the ETS and overlapping policies (van den Bergh et al., 2021). In this situation, the coherence of the resulting policy mix can be thought of as how well unintended interactions can be reduced, and intended ones lead to no adverse effects on the desired goals in question. In relation to an ETS, this means that interactions neither cause an expansion of the cap, i.e., a loss of stringency, nor a reduction in cost-effectiveness (de Perthuis \& Trotignon, 2014). In an ETS with a fixed cap, no additional policy in the mix affects total abatement, irrespective of the nature of the policy interaction, unless it directly targets the supply of allowances, as in the case of allowance cancellations. In consequence, overlapping policies that target emissions, i.e., the demand for allowances, change the ranking of abatement options. Unless this ranking was already distorted by a market failure other than the climate externality, an intervention reduces cost-effectiveness (Sorrell \& Sijm, 2003). In the presence of other distortions, additional policies have the potential to increase the static and dynamic efficiency of the policy mix (de Perthuis \& Trotignon, 2014).

In principle, the carbon neutrality of policies overlapping with a fixed-cap ETS allows for a coherent policy mix. This could be achieved if overlapping policies were exclusively designed to address market failures other than the pollution externality. A policy that addresses only lock-in effects or innovation spillovers would then be fully coherent. However, in practice, most climate policies such as support schemes for renewables (Boasson et al., 2020), coal phase-outs (Keles \& Yilmaz, 2020), or energy efficiency measures (Perino \& Pioch, 2017) overlapping the EU ETS explicitly aim to reduce carbon emissions. Given the aspiration of these policies to reduce emissions and the fixed cap in the pre-2019 EU ETS, the EU's climate policy mix was incoherent (see Table 1) since it did not achieve more abatement than the EU ETS alone but increased total costs (Böhringer et al., 2009).

Table 1. Modes of interactions between instruments in a policy mix.

\begin{tabular}{|c|c|c|c|}
\hline \multicolumn{4}{|c|}{$\begin{array}{l}\text { Performance of the policy mix (here: abatement achieved) } \\
\text { instrument \#1 alone: } a_{1} ; \text { instrument } \# 2 \text { alone: } a_{2} ; \text { with } a_{1}, a_{2}>0 ; a_{1}>a_{2}\end{array}$} \\
\hline Mode of interaction & & policy mix \#1 + \#2 & Performance of the mix is... \\
\hline \multirow{2}{*}{ coherent } & synergistic & $>a_{1}+a_{2}$ & higher than the sum of the single instruments. \\
\hline & neutral & $a_{1}+a_{2}$ & equal to the sum of the single instruments. \\
\hline coherent if cost effective & conflicting & $a_{1} \leq m<a_{1}+a_{2}$ & $\begin{array}{l}\text { higher than for the best single instrument in the mix but } \\
\text { lower than the sum of the single instruments. }\end{array}$ \\
\hline incoherent & backfiring & $<a_{1}$ & lower than for the best single instrument in the mix. \\
\hline
\end{tabular}

Source: adapted from van den Bergh et al. (2021). 
Policies aiming at emission reductions overlapping an ETS with a fixed cap are fully effective if they target the supply of allowances rather than demand, i.e., pollution sources. Cancellation or retirement of allowances have been used both by governments (Government Offices of Sweden, 2016) and NGOs. Apart from such discretionary, stand-alone interventions, cancellations can complement demand-reducing policies to ensure that total emissions are reduced. This combined approach is backed by Art. 12(4) of the EU ETS Directive and has been legislated as part of the German coal phase-out (European Union, 2003; Osorio et al., 2020). Nevertheless, abatement policies supplemented by allowance cancellations have a substantial drawback: They force society to pay twice, first for the increase in abatement and possibly infrastructural transformation costs, and second for the purchase of allowances to be cancelled. Additional abatement would be much cheaper if one merely cancelled allowances and left it to market participants to decide which plants to close down for compliance with the more stringent cap. According to the definition above, combining abatement policies with cancellations in a fixed-cap ETS constitutes an incoherent policy mix.

So-called flexibility mechanisms establish transparent rules for supply adjustments. Simple variants are price floors, ceilings, and collars (de Perthuis \& Trotignon, 2014; del Río \& Cerdá, 2017; van den Bergh et al., 2021), but any monotonous relationship between the allowance price and the number of allowances issued could be established (Burtraw et al., 2020; Pizer, 2002; Roberts \& Spence, 1976). A hybrid system combines aspects of a tax with an ETS allowing the regulator to choose a bliss point between both extremes (Traeger et al., 2020). This flexibility brings about the possibility to stabilise price paths, control for conflicts between overlapping policies, and manage allowance supply in reaction to unforeseen shocks. A reduction in demand can thus be fully or partially channelled towards a reduction of the cap or a decrease in the price for allowances. This does not make the policy mix less cost-ineffective, but it allows to address concerns of market participants and policymakers who favour a reliable price signal or want other climate policies to feature a climate benefit. A flexibility mechanism does not do away with the basic tradeoff that each change in market fundamentals translates either into a price or an emission response. However, it does allow the policymaker to split the impact between these channels rather than being bound to a fixed-cap ETS (only price response) or a carbon tax (only emission response).

\section{The Incoherence of the EU Emissions Trading System in the Policy Mix}

The source of policy incoherence of the EU's current climate policy mix stems from the modifications the MSR made to the EU ETS, which impact the supply of allowances by two interrelated mechanisms. Firstly, it reduces supply by taking in allowances when the TNAC is above an upper value and increases it by releasing allowances when the TNAC falls below a lower value. This mechanism adjusts the allocation schedule but does itself not affect the cumulative cap (Perino \& Willner, 2016). Secondly, the MSR's cancellation mechanism keeps the number of allowances it holds for later release below a predefined level. The cumulative cap decreases by the number of allowances cancelled by the MSR, and due to the reserve's current holdings, every allowance now entering the reserve by the first mechanism will eventually be cancelled. The two mechanisms work non-discretionary along preset parameters, and the quantity of cancellations by the latter depends on the former's intake over time (Perino, 2018). Because the MSR thus reacts to changes in actual emissions, the effectiveness of the EU ETS is now endogenously linked to overlapping policies and subject to substantial uncertainty (Bruninx et al., 2020; Osorio et al., 2021). The rationale is that this rule-based link between actual emissions and the supply of allowances would allow overlapping policies to contribute to abatement. Meanwhile, the public debate seems largely unperturbed by objections that there already is a policy instrument in place that makes sure that coal-fired power stations will become unprofitable and hence go out of business in the near future (Pietzcker et al., 2021). If this argument is noticed, a typical response is that this proves that the ETS needs to be adjusted instead of changing or discarding the overlapping policy.

The MSR's bane with regard to policy coherence lies in its indicator for scarcity, the TNAC. To understand why, it is crucial to see the link between the time profile of allowance demand and how the dynamic supply adjustment stipulated by the MSR reacts to it. Market participants store allowances for future use in the expectation of scarcity, i.e., the future availability of allowances. They store more allowances when they expect greater scarcity in the future, e.g., by a steeper decrease of the cap in line with new climate targets, or they store fewer allowances when they expect less scarcity, e.g., as a result of anticipated overlapping policies or technology shocks and their effect on the speed of decarbonisation (Gerlagh et al., 2021; Karp \& Traeger, 2021; Perino et al., 2020). Many circumstances determine market behaviour. The constant adaptation of expectations and the processing of information is reflected in the market price. In other words, if it is perceived or expected that future scarcity will be low, prices will be low, and vice versa. This is the result of intertemporal arbitrage, which improves the cost-effectiveness of the system as market participants use available information to engage in abatement and investment at least cost to themselves. However, the MSR responds very differently to changes in immediate scarcity as compared to changes in expected scarcity.

It is capable of credibly reducing market imbalances that resulted from the glut in allowances caused by the economic turmoil in 2008 and numerous 
emission-reducing policies at the EU and MS levels (Koch et al., 2014). The same is true for unforeseen shocks leading to supply-demand imbalances in an ad-hoc fashion, such as the Covid-19-induced economic recession in 2020 and 2021 (Gerlagh et al., 2020). Immediate reductions in emissions increase the TNAC and hence intake and cancellations by the MSR. Then, the MSR reacts in the manner of any vendor of commodities in any market and reduces supply when faced with reduced demand. This is a beneficial interaction with the policy mix as it increases the system's stability and forestalls additional measures on either the EU or MS level.

Contrarily, if an overlapping policy induces a change in future scarcity, the MSR's response is likely to backfire. Anticipation of a reduction in the future demand for allowances, e.g., due to a coal phase-out, reduces prices and increases emissions already today, i.e., before actual policy-induced abatement takes place. Hence, the TNAC decreases, MSR intake drops, and fewer allowances are cancelled. Everything else being equal, the additional impact of announcing the closing down of an emission source in the future is to increase total GHG emissions within the EU ETS (Gerlagh et al., 2021; Perino et al., 2020; Rosendahl, 2019). Vice versa, if market participants expect an increase in scarcity in the future, as has been the case since the EU announced its more ambitious climate goals in the autumn of 2020, prices and the TNAC increase, emissions drop and the MSR increases scarcity further by cancelling more allowances. The way the MSR "punctures the waterbed" creates interactions between the EU ETS and (future) overlapping climate policies that are detrimental to both total abatement and cost-effectiveness of the policy mix. Instead of fostering synergies, the MSR reduces incoherence for short-term measures but pushes long-term policies that are important to create credible investment signals into the backfiring range (Table 1). If e.g., MS wanted to avoid the MSR backfiring, their additional climate policies would have to mimic sudden shocks and happen unannounced and erratically. Clearly, this cannot be prudent advice to policymakers.

The TNAC is not fit to inform dynamic supply adjustment in reaction to demand changes from expected changes of scarcity. Changing the parameter values of the MSR within the current design only affects how strongly the MSR responds to changes in the TNAC. It cannot address the problem that the MSR causes overlapping policies to backfire. Whatever makes the MSR less responsive to change in the TNAC brings the EU ETS back closer to the former design with a fixed cap. Whatever renders the cap more sensitive to change in the TNAC increases both the emission impact of immediate abatement measures but also the extent to which pre-announced efforts backfire. The MSR adjustments proposed by the EC as part of the "Fit for 55" package would do the latter. As long as existing parameters are only tweaked and the channel of interaction between the MSR's short-run supply adjustment mechanism in the form of the TNAC remains, incoherence will persist as well.

Cap adjustments that respond in the same and coherent way to both immediate and pre-announced overlapping climate policies need to respond to the allowance price rather than the TNAC (Gerlagh et al., 2021; Perino et al., 2020). Such a price-based cap adjustment would also respond much better to technology shocks and other sources of uncertainty (Karp \& Traeger, 2021; Traeger et al., 2020). A price-based cap adjustment is not restricted to price floors or corridors (Flachsland et al., 2020). It extends to all (weakly) upward-sloping supply curves for allowances. For example, it could define that for a particular price increase, the number of allowances be extended or contracted by a specific amount or percentage. This is very much in line with the mechanism contained in Art. 1(7) of Decision 2015/1814 in conjunction with Art. 29a(1) of Directive 2003/87/EC (European Union, 2003, 2015). However, this price-based approach serves as an emergency mechanism only, i.e., it is very unlikely to be triggered and activation is, unlike the TNAC-based interventions, not automatic but conditional on approval by a committee.

While the current MSR makes it practically impossible to reliably predict the emission and price impacts of overlapping climate policies, a price-based supply adjustment would transparently specify these impacts, as they are determined by the slope of the allowance supply function-which is the same regardless of the source of the change in allowance demand. The latter is very much in contrast to today's MSR, where the size and direction of the cap adjustment depends primarily on the timing of the overlapping policy (Perino et al., 2020). Importantly, such a price-based cap adjustment can be designed to be consistent with the requirements for qualified majorities in the EU legislative process (Perino et al., 2021).

\section{Conclusion}

Until the end of 2022, the EU will decide how to reform the European carbon market in accordance with the broader legislative agenda under the Green Deal. Credible and stable pricing is needed to sustainably steer socio-economic transformation towards a decarbonised future, yet the MSR both destabilises the market and obscures participants' and MS' elicitation of causal links between a change in demand and market outcomes (Perino et al., in press). Instead, well-intended unilateral action by MS to increase abatement is weakened or even backfires, leading to higher than optimal compliance costs (Perino et al., 2020; Zaklan et al., 2021).

As the historically amassed TNAC dwindles over the next few years and an increasing number of overlapping policies enter the policy mix, expectations about future scarcity will dominate price and TNAC movements ever more strongly. Then, the incoherence of the climate policy mix in the ETS sector caused by the MSR will also become more prominent. A first glimpse of this was seen 
in May 2021 when allowance prices defied the Covidinduced recession and exceeded $50 €$ for the first time, after having roughly doubled in the previous months. At the same time, the Commission announced the most recent TNAC value that triggered a substantial further reduction in the supply of almost 380 million allowances, second only to the figure of 397 million announced in May 2019. Cancelling allowances in response to a recession is fine in principle; however, if this is done at a time when other events dominate the allowance market, as reflected in the price rally, additional cancellations destabilise it. It will become even more important to guarantee that climate and related policies passed by MS do not impede the cost-effectiveness of the EU ETS, that the EU ETS does not impede on the abatement effectiveness of $\mathrm{MS}^{\prime}$ policies, and that the latter do not impede each other through their connection through the shared cap and price mechanism of the carbon market.

However, changes to the EU ETS proposed by the EC in the "Fit for 55 Package" on 14 July 2021 are confined to tweaks of parameters leading to minor improvements in the functioning of the market but do not address the underlying problem of structural incoherence emanating from the MSR. On the contrary, the same flaw in the design is bound to impair the second ETS envisioned for the transport and housing sectors, as the EC proposes a slightly different yet equally incoherent TNAC-triggered reserve (European Commission, 2021a, 2021b). Taking a deeper look into the Impact Assessment Report to observe the EU's Better Regulation Toolbox in action, one learns about coherence with horizontally overlapping policies, such as looking at complementarities between extending the scope of the carbon market and energy efficiency measures, yet the more prevalent vertical aspects are left out of the discussion (European Commission, 2021a, p. 11). Then again, the MSR is supposed to generally enhance coherence with overlapping policies by mitigating demand fluctuations (European Commission, 2021a, p. 144). What becomes clear by this reading is the disparity between aspiration and result, and the lack of insight into the structural flaw of the system's current design, which afflicts overlapping policies no matter whether they interact horizontally or vertically with the EU ETS. What is needed is the replacement of the TNAC as the indicator for scarcity. As proposed in Section 3, a price-based supply adjustment mechanism would not dismantle the fundamental logic of the carbon market and cap-and-trade but rather turn currently backfiring interactions into conflicting to neutral ones with the degree open to choice by the regulator. As a possible obstacle, it would require the EU to transparently specify how to trade off reductions in total emissions against reductions in the financial burden borne by firms and households, which is exactly what the price-responsiveness of the cap determines. If Wettestad and Jevnaker (2019) are correct in their assessment that the recent rules are a result of "smokescreen politics" aiming at obscuring key trade-offs, chances for such a move towards an EU ETS design that enables rather than undermines the coherence of the EU climate policy mix seem dim.

\section{Acknowledgments}

Both authors acknowledge financial support from ARIADNE funded by the Federal Ministry of Education and Research of Germany (project no. 03SFK5SO). In addition, Perino's research is supported by the German Research Foundation (DFG) under Germany's Excellence Strategy, cluster EXC 2037 "Climate, Climatic Change, and Society" (project no. 390683824). The authors are thankful for the support granted by PaG's staff and the enriching comments of three anonymous reviewers.

\section{Conflict of Interests}

The authors declare no conflict of interest.

\section{References}

Bayer, P., \& Aklin, M. (2020). The European Union emissions trading system reduced $\mathrm{CO} 2$ emissions despite low prices. Proceedings of the National Academy of Sciences, 117(16), 8804-8812. https://doi.org/ 10.1073/pnas.1918128117

Boasson, E. L., Leiren, M. D., \& Wettestad, J. (2020). Introduction. In E. L. Boasson, M. D. Leiren, \& J. Wettestad (Eds.), Comparative renewables policy: Political, organizational and European fields (pp. 3-18). Routledge. https://doi.org/10.4324/9780429198144

Böhringer, C., Rutherford, T. F., \& Tol, R. S. (2009). The EU 20/20/2020 targets: An overview of the EMF22 assessment. Energy Economics, 31, S268-S273. https://doi.org/10.1016/j.eneco.2009.10.010

Bruninx, K., Ovaere, M., \& Delarue, E. (2020). The long-term impact of the market stability reserve on the EU emission trading system. Energy Economics, 89, Article 104746. https://doi.org/10.1016/j.eneco. 2020.104746

Burtraw, D., Holt, C., Palmer, K., \& Shobe, W. (2020). Quantities with prices: Price-responsive allowance supply in environmental markets (Working Paper 20-17). Resources for the Future. https://www.rff. org/publications/working-papers/quantities-pricesprice-responsive-allowance-supply-environmentalmarkets

Coscieme, L., Mortensen, L. F., \& Donohue, I. (2021). Enhance environmental policy coherence to meet the Sustainable Development Goals. Journal of Cleaner Production, 296, Article 126502. https://doi. org/10.1016/j.jclepro.2021.126502

de Jong, E., \& Vijge, M. J. (2021). From Millennium to Sustainable Development Goals: Evolving discourses and their reflection in policy coherence for development. Earth System Governance, 7, Article 100087. https://doi.org/10.1016/j.esg.2020.100087 
de Perthuis, C., \& Trotignon, R. (2014). Governance of $\mathrm{CO}_{2}$ markets: Lessons from the EU ETS. Energy Policy, 75, 100-106. https://doi.org/10.1016/j.enpol.2014. 05.033

del Río, P., \& Cerdá, E. (2017). The missing link: The influence of instruments and design features on the interactions between climate and renewable electricity policies. Energy Research \& Social Science, 33, 49-58. https://doi.org/10.1016/j.erss.2017.09.010

del Río, P., Klessmann, C., Winkel, T., \& Gephart, M. (2013). Interactions between EU GHG and renewable energy policies-How can they be coordinated (work package 7, deliverable 7.2, Report D6.1b). beyond2020. https://www.res-policy-beyond2020. eu/downloads.html

Eichner, T., \& Pethig, R. (2019). EU-type carbon regulation and the waterbed effect of green energy promotion. Energy Economics, 80, 656-679. https://doi. org/10.1007/s11149-010-9118-z

Ellerman, A. D., \& Buchner, B. K. (2007). The European Union emissions trading scheme: Origins, allocation, and early results. Review of Environmental Economics and Policy, 1(1), 66-87. https://doi.org/ 10.1093/reep/rem003

European Commission. (2019). The EU's efforts to simplify legislation-2020 annual burden survey. https://ec.europa.eu/info/files/eus-efforts-simplifylegislation-2020-annual-burden-survey_en

European Commission. (2021a). Proposal for a Directive of European Parliament and of the Council amending Directive 2003/87/EC establishing a system for greenhouse gas emission allowance trading within the Union, Decision (EU) 2015/1814 concerning the establishment and operation of a market stability reserve for the Union greenhouse gas emission trading scheme and Regulation (EU) 2015/757 (COM(2021) 551 final).

European Commission. (2021b). Proposal for a Decision of the European Parliament and the Council amending Decision (EU) 2015/1814 as regards the amount of allowances to be placed in the market stability reserve for the Union greenhouse gas emission trading scheme until 2030 (COM(2021) 571 final).

European Commission. (2021c). Publication of the total number of allowances in circulation in 2020 for the purpose of the Market Stability Reserve under the EU Emissions Trading System established by Directive 2003/87/EC (Communication from the Commission, C(2021) 3266 final).

European Commission. (2021d). Report from the Commission to the European Parliament and the Council on the Functioning of the European Carbon Market in 2020 pursuant to Articles 10(5) and 21(2) of Directive 2003/87/EC (as amended by Directive 2009/29/EC and Directive (EU) 2018/410) (COM(2021) 962 final).

European Commission. (2021e). Better regulation guidelines (Commission Staff Working Document SWD(2021)305). https://ec.europa.eu/info/law/law- making-process/planning-and-proposing-law/betterregulation-why-and-how/better-regulationguidelines-and-toolbox_en

European Commission. (2021f). "Better regulation" toolbox (Complement to Commission Staff Working Document SWD(2021)305).

European Environment Agency. (2020). Trends and projections in Europe 2020-Tracking progress towards Europe's climate and energy targets (EEA Report, 13/2020). https://www.eea.europa.eu/ publications/trends-and-projections-in-europe2020

European Environment Agency. (2021). EU Emissions Trading System (ETS) data viewer [Data set]. https://www.eea.europa.eu/data-and-maps/ dashboards/emissions-trading-viewer-1

European Union. (2003). Directive 2003/87/EC of the European Parliament and of the Council of 13 October 2003 establishing a system for greenhouse gas emission allowance trading within the Union and amending Council Directive 96/61/EC (Consolidated version of 01.01.2021, OJ L275/46). https://eur-lex. europa.eu/eli/dir/2003/87/2021-01-01

European Union. (2012). Consolidated version of the Treaty on the Functioning of the European Union (OJ C326/55). https://eur-lex.europa.eu/legal-content/ EN/TXT/?uri=OJ:C:2012:326:TOC

European Union. (2015). Decision (EU) 2015/1814 of the European Parliament and of the Council of 6 October 2015 concerning the establishment and operation of a market stability reserve for the Union greenhouse gas emission trading scheme and amending Directive 2003/87/EC (OJ L264/58). https://eur-lex. europa.eu/legal-content/EN/TXT/?uri=CELEX\% 3A02015D1814-20180408

Fais, B., Blesl, M., Fahl, U., \& Voß, A. (2015). Analysing the interaction between emission trading and renewable electricity support in TIMES. Climate Policy, 15(3), 355-373. https://doi.org/10.1080/14693062. 2014.927749

Fankhauser, S., Hepburn, C., \& Park, J. (2010). Combining multiple climate policy instruments: how not to do it. Climate Change Economics, 1(3), 209-225. https:// doi.org/10.1142/S2010007810000169

Flachsland, C., Pahle, M., Burtraw, D., Edenhofer, O., Elkerbout, M., Fischer, C., Tietjen, O., \& Zetterberg, L. (2020). How to avoid history repeating itself: the case for an EU Emissions Trading System (EU ETS) price floor revisited. Climate Policy, 20(1), 133-142. https://doi.org/10.1080/14693062.2019.1682494

Gerlagh, R., Heijmans, R. J., \& Rosendahl, K. E. (2020). Covid-19 tests the market stability reserve. Environmental and Resource Economics, 76(4), 855-865. https://doi.org/10.1007/s10640-020-00441-0

Gerlagh, R., Heijmans, R. J., \& Rosendahl, K. E. (2021). An endogenous emissions cap produces a green paradox. Economic Policy, 36(107), 485-522. https://doi. org/10.1093/epolic/eiab011 
Government Offices of Sweden. (2016, July 2). Real emission reductions and more pressure on the EU due to new Swedish EU ETS policy [Press release]. https://www.government.se/press-releases/2016/ 07/real-emission-reductions-and-more-pressureon-the-eu-due-to-new-swedish-eu-ets-policy

International Carbon Action Partnership. (2021). China national ETS (ETS detailed information, version of 23.07.2021). https://icapcarbonaction.com/en/etsmap

Karp, L., \& Traeger, C. P. (2021). Smart cap (CEPR Discussion Paper DP15941). Centre for Economic Policy Research. https://ssrn.com/abstract=3816814

Keles, D., \& Yilmaz, H. Ü. (2020). Decarbonisation through coal phase-out in Germany and EuropeImpact on emissions, electricity prices and power production. Energy Policy, 141, Article 111472. https://doi.org/10.1016/j.enpol.2020.111472

Kern, F., \& Howlett, M. (2009). Implementing transition management as policy reforms: A case study of the Dutch energy sector. Policy Sciences, 42, Article 391. https://doi.org/10.1007/s11077-009-9099-x

Koch, N., Fuss, S., Grosjean, G., \& Edenhofer, O. (2014). Causes of the EU ETS price drop: Recession, CDM, renewable policies or a bit of everything? New evidence. Energy Policy, 76, 676-685. https://doi.org/ 10.1016/j.enpol.2014.06.024

Nilsson, M., Zamparutti, T., Petersen, J. E., Nykvist, B., Rudberg, P., \& McGuinn, J. (2012). Understanding policy coherence: Analytical framework and examples of sector-environment policy interactions in the EU. Environmental Policy and Governance, 22(6), 395-423. https://doi.org/10.1002/eet.1589

Osorio, S., Pietzcker, R. C., Pahle, M., \& Edenhofer, O. (2020). How to deal with the risks of phasing out coal in Germany. Energy Economics, 87, Article 104730. https://doi.org/10.1016/j.eneco.2020.104730

Osorio, S., Tietjen, O., Pahle, M., Pietzcker, R. C., \& Edenhofer, O. (2021). Reviewing the Market Stability Reserve in light of more ambitious EU ETS emission targets. Energy Policy, 158, Article 112530. https:// doi.org/10.1016/j.enpol.2021.112530

Perino, G. (2018). New EU ETS Phase 4 rules temporarily puncture waterbed. Nature Climate Change, 8(4), 262-264. https://doi.org/10.1038/s41558-0180120-2

Perino, G., Pahle, M., Pause, F., Quemin, S., Scheuing, H., \& Willner, M. (2021). EU ETS stability mechanism needs new design (CEN Policy Brief). Center for Earth System Research and Sustainability, Universität Hamburg. http://uhh.de/cen-eu-ets

Perino, G., \& Pioch, T. (2017). Banning incandescent light bulbs in the shadow of the EU emissions trading scheme. Climate Policy, 17(5), 678-686. https://doi. org/10.1080/14693062.2016.1164657

Perino, G., Ritz, R. A., \& van Benthem, A. (2020). Overlapping climate policies (NBER Working Paper No. 25643). National Bureau of Economic Research. https://doi.org/10.3386/w25643

Perino, G., \& Willner, M. (2016). Procrastinating reform: The impact of the market stability reserve on the EU ETS. Journal of Environmental Economics and Management, 80, 37-52. https://doi.org/10.1016/j.jeem. 2016.09.006

Perino, G., \& Willner, M. (2017). EU-ETS Phase IV: allowance prices, design choices and the market stability reserve. Climate Policy, 17(7), 936-946. https:// doi.org/10.1080/14693062.2017.1360173

Perino, G., Willner, M., Quemin, S., \& Pahle, M. (in press). Policy Brief-The EU ETS Market Stability Reserve: Does It Stabilize or Destabilize the Market? Review of Environmental Economics and Policy.

Pietzcker, R. C., Osorio, S., \& Rodrigues, R. (2021). Tightening EU ETS targets in line with the European Green Deal: Impacts on the decarbonization of the EU power sector. Applied Energy, 293, Article 119253. https://doi.org/10.1016/j.apenergy.2021.116914

Pizer, W. A. (2002). Combining price and quantity controls to mitigate global climate change. Journal of Public Economics, 85(3), 409-434. https://doi.org/ 10.1016/S0047-2727(01)00118-9

Roberts, M. J., \& Spence, M. (1976). Effluent charges and licenses under uncertainty. Journal of Public Economics, 5(374), 193-208. https://doi.org/10.1016/ 0047-2727(76)90014-1

Rosendahl, K. E. (2019). EU ETS and the waterbed effect. Nature Climate Change, 9(10), 734-735. https://doi. org/10.1038/s41558-019-0579-5

Sandström, A., Söderberg, C., Lundmark, C., Nilsson, J., \& Fjellborg, D. (2020). Assessing and explaining policy coherence: A comparative study of water governance and large carnivore governance in Sweden. Environmental Policy and Governance, 30(1), 3-13. https://doi.org/10.1002/eet.1871

Sianes, A. (2013). Shedding light on policy coherence for development: A conceptual framework. Journal of International Development, 29(1), 134-146. https:// doi.org/10.1002/jid.2977

Söderberg, C. (2016). Complex governance structures and incoherent policies: Implementing the EU water framework directive in Sweden. Journal of Environmental Management, 183, 90-97. https://doi.org/ 10.1016/j.jenvman.2016.08.040

Sorrell, S., \& Sijm, J. (2003). Carbon trading in the policy mix. Oxford Review of Economic Policy, 19(3), 420-437. https://doi.org/10.1093/oxrep/19.3.420

Traeger, C., Perino, G., Pittel, K., Requate, T., \& Schmitt, A. (2020). The Flexcap-An innovative CO2 pricing for Germany. In C. Hainz (Ed.), ifo DICE Report 1/2020 (Spring): Carbon pricing (pp. 42-48). ifo Institut. https://www.ifo.de/publikationen/2020/aufsatzzeitschrift/flexcap-innovative-co2-pricing-germany

van den Bergh, J., Castro, J., Drews, S., Exadaktylos, F., Foramitti, J., Klein, F., Konc, T., \& Savin, I. (2021). Designing an effective climate-policy mix: accounting for instrument synergy. Climate Policy, 
21(6), 745-764. https://doi.org/10.1080/14693062. 2021.1907276

Verschaeve, J., Delputte, S., \& Orbie, J. (2016). The rise of policy coherence for development: A multicausal approach. European Journal of Development Research, 28, 44-61. https://doi.org/10.1057/ejdr. 2015.74

Wettestad, J., \& Jevnaker, T. (2019). Smokescreen politics? Ratcheting up EU emissions trading in 2017.
Review of Policy Research, 36(5), 635-659. https:// doi.org/10.1111/ropr.12345

Zaklan, A., Graichen, J., Graichen, V., Hermann, H., \& Cludius, J. (2021). Structural supply side management in the EU ETS: Reviewing the Market Stability Reserve (Climate Change 39/2021). German Environment Agency. https://www.umweltbundesamt.de/ publikationen/structural-supply-side-managementin-eu-ets

\section{About the Authors}

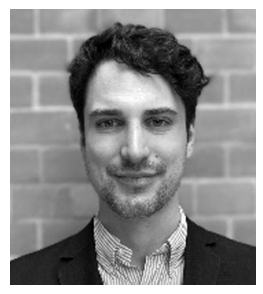

Maximilian Willner is a postdoctoral researcher in economics at the University of Hamburg, Germany, and works on a range of topics related to climate policy. Projects include in-depth theoretical analyses of the EU ETS and carbon markets in general, border carbon adjustment mechanisms, carbon-sink mobilisation, and the political economy of abatement instrument choice. He serves on multiple advisory boards for environmental and climate policy in the political sphere and actively engages in the societal debate concerning the direction and shape of economic transformation.

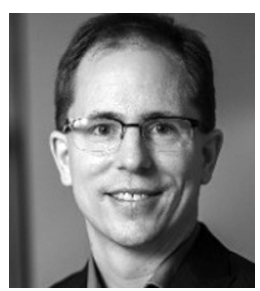

Grischa Perino is a professor of economics at the University of Hamburg, Germany. His research focuses on the choice, design, impact, and interaction of climate policy instruments. An expert on the EU ETS, he has markedly contributed to the understanding of the Market Stability Reserve (MSR) over the past years and has consulted the European Commission and the German Emission Trading Authority on the MSR. He is a principal investigator within the German Cluster of Excellence "Climate, Climate Change and Society" and serves as co-editor at Environmental and Resource Economics. 